\title{
Anisocoria after anesthesia induction caused by Adie syndrome
}

\author{
Mariko Ishihara $\cdot$ Ryota Aoi $\cdot$ Kan Takahashi
}

Received: 26 June 2014 / Accepted: 29 July 2014/Published online: 20 August 2014

(C) Japanese Society of Anesthesiologists 2014

To the Editor:

A 49-year-old woman underwent general anesthesia. She had no history of neurological or intracranial diseases. We were not aware of her anisocoria. She was intubated with stable hemodynamics. After induction, she exhibited anisocoria (pupil diameters of $2 \mathrm{~mm}$ and $6.5 \mathrm{~mm}$ on the right and left side, respectively). Suspecting stroke, we immediately awoke her. She exhibited no neurological abnormalities and then informed us of her history of Adie syndrome. After she awoke completely, her anisocoria persisted $(3.5 \mathrm{~mm}$ on her right and $6.0 \mathrm{~mm}$ on her left). Light reflex was quick on the right and slow on the left. Two days later, the surgery was completed uneventfully.

Previous reports have shown cases of anisocoria in the absence of any neurological deficit. In these cases, anisocoria was caused by damage of the iris sphincter muscle from past trauma [1], and Adie syndrome [2].

The main symptoms of Adie syndrome consist of anisocoria and loss or weakness of the light reflex. These symptoms can become exacerbated as a result of the parasympathetic dominance caused by anesthetics.
Therefore, we considered that her anisocoria appeared markedly following anesthesia induction.

Pupillary examination is often omitted unless the patient has a history of neurological disease. In our case, preoperative awareness of her abnormal pupils and her history of Adie syndrome could have avoided postponement of the surgery. We recommend that pupillary examination to check the existence of anisocoria and the light reflex should be performed during the preoperative anesthetic assessment for all patients.

\section{References}

1. Aceto P, Perilli V, Vitale F, Sollazzi L. Effect of anesthesia in a patient with pre-existing anisocoria. Eur Rev Med Pharmacol Sci. 2011;15:211-3.

2. Kobayashi M, Takenami T, Kimotsuki H, Mukuno K, Hoka S. Adie syndrome associated with general anesthesia. Can J Anesth. 2008;55:130-1.

\footnotetext{
M. Ishihara ( ()

Department of Anesthesia, Sakai City Hospital, 1-1-1

Minamiyasui-cho, Sakai-ku, Osaka, Sakai, Japan

e-mail: mariko_i@muc.biglobe.ne.jp

R. Aoi

Department of Anesthesia, Sakai City Hospital, Osaka, Japan

K. Takahashi

Department of Critical Care and Intensive Care Medicine, Shiga

University Medical Science, Shiga, Otsu, Japan
} 